\title{
The Road to Improving Home Oxygen Access: Research, Education, and Advocacy
}

Supplemental oxygen has been the standard of care for management of hypoxemia for $>30 \mathrm{y} .{ }^{1}$ However, recent investigations have raised concerns about oxygen access, portable systems, patient education, safety, adherence, clinical effectiveness, and clinician training. ${ }^{2-5}$ A qualitative study by Arnold et $\mathrm{al}^{6}$ found a range of oxygen-related challenges, including fear of running out of oxygen, systems too heavy to carry, embarrassment of use in public, and a lack of oxygen use outside the home for those without caregivers. Oxygen users with severe COPD have decreased physical activity levels, exercise capacity, quality of life (QOL), and social interaction. ${ }^{7}$ It remains unclear to what degree disease severity, type of oxygen system use, or other factors decrease mobility and independence in home oxygen users. ${ }^{4}$

In this issue of Respiratory CARe, AlMutairi et $\mathrm{al}^{4} \mathrm{de}^{\mathrm{d}}$ scribed a qualitative analysis of 311 subjects' responses to an open-ended question about patients' perceptions regarding long-term oxygen therapy. Their findings support a substantial negative impact of long-term oxygen therapy devices on patient-centered outcomes, including reduction in QOL, with decreased mobility and increased isolation experienced by users of heavier portable oxygen systems. These authors' use of a qualitative survey model captured important life changes and negative consequences described verbatim by respondents, which might be missed by using a quantitative approach. The key findings of decreased mobility, inadequate education, and loss of socialization that emerged from this rich patient-reported data were consistent with results of Lindell et $\mathrm{al}^{8}$ In a sample of 745 supplemental oxygen users with a variety of chronic lung diseases, qualitative analysis of responses to the question "Is there some issue, other than those mentioned above, that you are having related to your oxygen?" identified 3 themes of equipment issues, access to adequate portable systems, and related angst and worry.

There are critical and recurring issues that the investigation by AlMutairi et $\mathrm{al}^{4}$ highlighted. Matching the right equipment to the right patient is challenging. The lack of the prescriber's recommendations for an oxygen system can mean that a patient's oxygen device selection is determined by the durable medical equipment company or the payer, both of

The authors have disclosed no conflicts of interest.

DOI: $10.4187 /$ respcare.06666 whom have a stake in controlling equipment costs. A lack of prescriber education on what to expect from ambulatory oxygen therapy and its potential negative impact may leave patients unprepared for the challenges and complexities associated with ambulatory oxygen therapy that may negatively affect adherence. This survey documented other important inadequacies in current models of providing ambulatory oxygen therapy and the resulting patient frustration, isolation, desperation, and sense of powerlessness.

See the Original Study on Page 1321

The interface between patients, clinicians, durable medical equipment companies, and payers is fragmented with a framework structured to control costs, with little focus on clinician oversight, quality assurance, communication, and patientcentered outcomes. In an earlier large survey by Jacobs, et $\mathrm{al}^{5}$ 1,926 oxygen users with multiple chronic lung diseases, including COPD, reported a lack of clinician instruction of ambulatory oxygen therapy and feeling unprepared to operate the equipment. The majority reported multiple problems related to equipment malfunction, lack of physically manageable portable systems, and/or inadequate portable high-flow systems that limited the number of hours that they could leave their home.

The survey by AlMutairi et $\mathrm{al}^{4}$ also found decreased exercise capacity and social interaction in those with severe COPD who required long-term oxygen therapy that has previously been addressed by other investigators. Physical activity has been found to impact both hospitalization and mortality in COPD. ${ }^{9}$ Adherence to ambulatory oxygen therapy is often suboptimal, potentially limiting the clinician's impact of therapy. ${ }^{10,11}$ The role of clinician instruction has been found to play an important role in improving oxygen adherence. ${ }^{12} \mathrm{~A}$ study on the positive effects of ambulatory oxygen on QOL for patients with fibrotic lung disease and isolated exertional hypoxia was recently published. Investigators found a significant improvement in QOL, especially in activity and breathlessness domains, with the use of "lightweight portable oxygen" devices during exercise compared with not using portable oxygen with exercise. ${ }^{13}$

These 2 patient surveys, by AlMutairi et $\mathrm{al}^{4}$ and Jacobs et al, ${ }^{5}$ raise important concerns regarding patient isolation, decreased QOL, and reduction in physical activity 


\section{EDITORIALS}

associated with ambulatory oxygen therapy. Traditional outcome measures in oxygen clinical trials often ignore key impacts of ambulatory oxygen therapy, including adherence, physical activity, isolation, QOL, mood disorders, impact on employment, and other patient-centered outcomes. COPD is characterized by skeletal muscle dysfunction, disabling symptoms, and comorbidities. ${ }^{14} \mathrm{~A}$ decline in the availability of lightweight, long-lasting portable systems seemed to further limit mobility, physical activity, independence, and QOL in patients at high risk for frailty and poor outcomes. A lack of involvement by the clinical team further erodes the potential benefits of long-term oxygen therapy. In the survey by Jacob et al, ${ }^{5}$ most respondents reported not having their $\mathrm{S}_{\mathrm{pO}_{2}}$ assessed when equipment was delivered to their home, which highlights the absence of respiratory therapists in home oxygen provision.

The American Thoracic Society held multidisciplinary round table meetings in 2015 and 2016 based on anecdotal concerns from multiple patient and advocacy groups related to oxygen availability and durable medical equipment company service quality that coincided with expansion of the Competitive Bidding Program under the Centers for Medicare and Medicaid Services (CMS). The Competitive Bidding Program provides a reimbursement framework for Medicare beneficiaries who require oxygen. ${ }^{15}$ Under the Competitive Bidding Program, licensed durable medical equipment provider may submit a twice a day to provide equipment and supplies, including long-term oxygen therapy. Contracts are awarded annually by CMS based on preestablished pricing. Although a specific cause-and-effect relationship has not been established, durable medical equipment companies have moved to a model that limits oxygen delivery, liquid oxygen, and instruction and re-testing by respiratory therapists. Evaluation and reporting of patient-centered outcomes related to the Competitive Bidding Program framework are not publicly available. More recently, because of the recent data combined with the mobilization of multiple patient advocacy groups, CMS is now aware of concerns related to the reimbursement structure for liquid oxygen. More than 20 advocacy groups recently submitted comments on CMS-1691-P, the proposed rule for the Durable Medical Equipment, Prosthetics, Orthotics and Supplies, Competitive Bidding Program for calendar year 2019 regarding liquid oxygen and related issues.

Patient equipment and service concerns can be reported to the Medicare ombudsman by calling 1-800MEDICARE. This process is not widely used, possibly because patients do not understand the role, responsibilities, and complex interface of CMS, durable medical equipment companies, and prescribing clinicians, or who is responsible for errors and inadequate service. ${ }^{5}$ Prolonged call wait times may further deter patients from reporting concerns, particularly those who patients who are frail or ill. In the survey by Jacobs et al, ${ }^{5} 70 \%$ of the respondents were unaware of whom to call about oxygen problems or that the CMS ombudsman or COPD Information lines were available for unresolved problems. A significant increase in problems was reported by those living in the Competitive Bidding Program areas $(P=.03)$.

Although the findings of the survey by AlMutairi et $\mathrm{al}^{4}$ are critical to understanding and addressing inadequacies in current United States models of ambulatory oxygen therapy, the conclusions missed a couple of important aspects of current delivery of ambulatory oxygen therapy. Prescribing physicians may lack understanding of ambulatory oxygen therapy equipment features and availability in an environment in which durable medical equipment companies seem to determine portable equipment often based on financial decisions and, sometimes, regardless of patient appropriateness. Respiratory therapists and pulmonary rehabilitation clinicians have more depth of knowledge and experience in ambulatory oxygen therapy models and their role in mobility and ease of use.

Larger clinical trials are needed to evaluate the clinical benefits of ambulatory oxygen therapy as well as efficacy of smaller ambulatory systems, particularly related to enabling physical activity and independence. Use of larger, heavier ambulatory oxygen therapy systems needs to be evaluated for safety, effectiveness, and adherence versus lighter systems, particularly in patients who are deconditioned and frail; those with severe hypoxemia, comorbidities (eg, mood disorder, osteoporosis), fall risk; and physical barriers (including stairs). To define the role and impact of patient education, both by the prescribing physician and the respiratory therapist, clinician and supplier interface and quality metrics are needed. The efficacy and impact of ambulatory oxygen therapy on other lung diseases, including interstitial lung disease and pulmonary hypertension requires further investigation.

It is time for scientific and clinical societies to establish research priorities that are supported by government funding to address important uncertainties. The Medicare database holds important opportunities for collaborative understanding and possible resolution of existing challenges. Durable medical equipment companies need to be accountable to payers for appropriate quality and safety standards, and defined measures of client satisfaction, all of which should be public record. The American Thoracic Society, along with nearly every major scientific, clinical, and patient organization, has undertaken collaborative discussions, along with important representation and interest from CMS to identify inadequacies and gaps in care, and to develop an evidence-based approach to improve understanding, communication, and, ultimately, collaboration to establish strategies to improve processes and outcomes. This process will be slow and require extensive resources, and will not answer all challenges related to ambulatory oxygen therapy. 
It is difficult to ignore the ethical context of the evolution of portable oxygen availability, from the heavy E cylinders of the 1960s to lightweight, long-lasting liquid systems of the 1970s through the millennium, which have essentially disappeared after the establishment of the Competitive Bidding Program, and are now replaced with technology from 60 years ago. Compare this with CPAP used for treatment of obstructive sleep apnea, which has evolved into lightweight, quiet devices with wireless technology providing clinicians with a real-time apnea-hypopnea index, air leak, and adherence data, and the ability to remotely adjust pressure settings. CMS requirements for CPAP adherence and clinician reassessment within $90 \mathrm{~d}$ (vs annually with ambulatory oxygen therapy) further defines requirements of both the patient and prescribing clinician responsibilities, and has the potential to help facilitate communication and adherence.

The durable medical equipment company plays an important role of gatekeeper for CPAP adherence required for CPAP reimbursement. Both CPAP and ambulatory oxygen therapy share key features of a device for management of a common chronic respiratory condition, a prescribing clinician, equipment and service from a durable medical equipment company, and rules and payment from an insurer (often CMS), with nearly opposite trajectories of equipment quality and usability, and an effective durable medical equipment supplier-medical team-patient-payer interface. The other important ethical question is whether improved cost savings for oxygen provision has resulted in durable medical equipment companies being unable to fund provision of usable ambulatory oxygen therapy and respiratory therapists to address clinical education.

Models to define and support clinician roles are needed with intelligent electronic medical record programs designed to enable appropriate prescribing, clinical effectiveness, use of evidence-based methodologies, effective communication, patient satisfaction, QOL metrics, payer requirements, and durable medical equipment company interface, along with defining and enabling the role of the respiratory therapist in ambulatory oxygen therapy assessment and patient training. A collaborative effort that involves all the stakeholders, including advocacy groups, researchers, and scientific and professional societies, is needed and is slowly taking shape. Clearly, ambulatory oxygen therapy should not take your breath away. Mandates for systems that enable physical activity, independence, and QOL are part of the solution.

Chris Garvey FNP MSN MPA MAACVPR Sleep Disorders and Pulmonary Rehabilitation University of California, San Francisco San Francisco, California

Susan Jacobs RN MSc Stanford University School of Medicine Stanford, California

\section{REFERENCES}

1. Lacasse Y, Tan AM, Maltais F, Krishnan JA. Home oxygen in chronic obstructive pulmonary disease. Am J Respir Crit Care Med 2018;197(10):1254-1264.

2. Dobson and DaVanzo Associates. Access to Home Medical Equipment: Survey of Beneficiary, Case Manager and Supplier Experiences. 2017. http://www.aahomecare.org/uploads/userfiles/files/ documents/Studies/HME\%20Access\%20Study/Dobson_DaVanzo_ Patient_Access_Survey_Final_Report_10.11.17_FINAL.pdf. Accessed October 11, 2018.

3. Casaburi R. Long-term oxygen therapy: the three big questions. Ann Am Thorac Soc 2018;15(1):14-15.

4. AlMutairi H, Mussa CC, Lambert CTM, Vines DL, Strickland S. Perspectives from COPD subjects on portable LTOT devices. Respir Care 2018;63(11):1321-1330.

5. Jacobs SS, Lindell KO, Collins EG, Garvey CM, Hernandez C, McLaughlin S, et al. Patient perceptions of the adequacy of supplemental oxygen therapy: results of the American Thoracic Society Nursing Assembly Oxygen Working Group Survey. Ann Am Thorac Soc 2018;15(1):24-32.

6. Arnold E, Bruton A, Donovan-Hall M, Fenwick A, Dibb B, Walker E. Ambulatory oxygen: why do COPD patients not use their portable systems as prescribed? A qualitative study. BMC Pulm Med 2011;11-19.

7. Hartman JE, Boezen HM, de Greef MH, Ten Hacken NH. Physical and psychosocial factors associated with physical activity in patients with chronic obstructive pulmonary disease. Arch Phys Med Rehabil 2013;94(12):2396-2402.e7.

8. Lindell K O CL, Collins EG, Garvey CM, Hernandez C, McLaughlin S, Schneidman AM, Meek PM, Jacobs SS. Equipment, access and worry about running short of oxygen: key concerns in the patient supplemental oxygen survey. Am J Respir Crit Care Med 2017;195(A7646).

9. Garcia-Aymerich J, Lange P, Benet M, Schnohr P, Antó JM. Regular physical activity reduces hospital admission and mortality in chronic obstructive pulmonary disease: a population based cohort study. Tho$\operatorname{rax} 2006 ; 61(9): 772-778$.

10. Lacasse Y, Lecours R, Pelletier C, Bégin R, Maltais F. Randomised trial of ambulatory oxygen in oxygen-dependent COPD. Eur Respir J 2005;25(6):1032-1038.

11. Casaburi R, Porszasz J, Hecht A, Tiep B, Albert RK, Anthonisen NR, et al; COPD Clinical Research Network. Influence of lightweight ambulatory oxygen on oxygen use and activity patterns of COPD patients receiving long-term oxygen therapy. COPD 2012;9(1):3-11.

12. Pépin JL, Barjhoux CE, Deschaux C, Brambilla C. Long-term oxygen therapy at home: compliance with medical prescription and effective use of therapy. Chest 1996;109(5):1144-1150.

13. Visca D, Mori L, Tsipouri V, Fleming S, Firouzi A, Bonini M, et al. Effect of ambulatory oxygen on quality of life for patients with fibrotic lung disease (AmbOx): a prospective, open-label, mixedmethod, crossover randomised controlled trial. Lancet Respir Med 2018;6(10):759-770.

14. Global Initiative for Chronic Obstructive Lung Disease (GOLD). Global strategy for the diagnosis, management, and prevention of chronic obstructive pulmonary disease: 2018 report. https://goldcopd. org/wp-content/uploads/2017/11/GOLD-2018-v6.0-FINAL-revised20-Nov_WMS.pdf. Accessed October 11, 2018.

15. U.S. Department of Health and Human Services, U.S. Centers for Medicare and Medicaid Services (CMS), Medicare Learning Network. Home oxygen therapy. Baltimore, MD: CMS; Oct 2017. https:// www.cms.gov/Outreach-and-Education/Medicare-LearningNetwork-MLN/MLNProducts/Downloads/Home-Oxygen-TherapyICN908804.pdf. Accessed September 19, 2018. 